\title{
Application of Effective Stress Model to Analysis of Liquefaction and Seismic Performance of an Earth Dam in China
}

\author{
Changqing Qi, Wei Lu, Jimin Wu, and Xing Liu \\ School of Earth Sciences and Engineering, Hohai University, Nanjing 210098, China \\ Correspondence should be addressed to Changqing Qi; chqi79@gmail.com
}

Received 17 February 2015; Accepted 17 June 2015

Academic Editor: Francesco Tornabene

Copyright (C) 2015 Changqing Qi et al. This is an open access article distributed under the Creative Commons Attribution License, which permits unrestricted use, distribution, and reproduction in any medium, provided the original work is properly cited.

Earthquake-induced liquefaction is one of the major causes of catastrophic earth dam failure. In order to assess the liquefaction potential and analyze the seismic performance of an earth dam in Fujian, Southeastern China, the in situ shear wave velocity test was firstly carried out. Results indicate that the gravelly filling is a type of liquefiable soil at present seismic setting. Then the effective stress model was adopted to thoroughly simulate the response of the soil to a proposed earthquake. Numerical result generally coincides with that of the empirical judgment based on in situ test. Negative excess pore pressure developed in the upper part of the saturated gravelly filling and positive excess pore pressure developed in the lower part. The excess pore pressure ratio increases with depth until it reaches a maximum value of 0.45 . The displacement of the saturated gravelly soil is relatively small and tolerable. Results show that the saturated gravelly filling cannot reach a fully liquefied state. The dam is overall stable under the proposed earthquake.

\section{Introduction}

Earth dams usually have better seismic performance during earthquakes. According to statistics, seldom earth dams have been totally out of service after earthquakes in the past few decades in China [1]. But when the dam contains or is situated on liquefiable materials, earthquake-induced liquefaction may cause considerable reduction in stiffness and strength of soil, resulting in dam failure [2]. A number of dam failures or damages have been reported due to seismically induced liquefaction. The most classic example is the lower San Fernando dam during the 1971 San Fernando earthquake. Liquefaction induced flow slide on the upstream side of the dam nearly caused the dam to be out of service [3]. The liquefaction slide of Baihe dam of Miyun Reservoir during the 1976 Tangshan earthquake was another representative example. The estimated 0.15 million $\mathrm{m}^{3}$ volumetric slide in the upstream part of the dam aroused great panic at that time [4]. Several dam failures in Chilean [5], Japan [6], and India [7] were also reported causing great damage.

In sight of its immense economic damage and loss of life, earth dam failures due to liquefaction have drawn great concern in the past half century. Several types of approaches have been developed to study this problem. The empirical relationships based on tested indexes are commonly used methods at present [8-10]. The empirical relationship methods can give an overall and quick judgment on liquefaction potential of gravelly soil. But for thoroughly understanding the response of coarse soil to cyclic shear loads, numerical modeling technique is better [11-13]. The seismic response of soil has a direct relation to the progressive build-up of pore pressure during an earthquake. The increasing pore pressure and decreasing effective stress control the resistance of the soil to deformation [14]. Thus, assessment on progressive degradation of soil strength is important in dynamic soil liquefaction analysis.

The effective stress method is a useful tool in modeling the progressive loss of soil strength caused by development of pore pressure. Liyanapathirana and Poulos [15] summarized four main categories of liquefaction models based on effective stress analysis method, which are (1) models based on plasticity theory; (2) stress path methods; (3) correlations between pore pressure response and plastic volume change tendency; and (4) use of experimentally observed undrained pore pressure response. The model of the third category, which is often referred to as the Finn model, is explicit and has a lesser number of parameters. The model can take into account stiffness and strength degradation due to pore 
pressure development and was used in this paper for dam liquefaction and seismic performance assessment.

\section{Methodology}

The strength and stiffness of soil are primarily governed by effective stress, and so it is desirable to evaluate seismic response of soil in terms of effective stress. For saturated granular material, adopted numerical model should reflect the variation of pore pressure and thus can predict the effective stress level.

For saturated soil under undrained conditions, Martin et al. [16] suggested that the pore pressure increment is related to the change of plastic volumetric strain of the soil skeleton:

$$
\Delta u=-\frac{1}{C_{b}} \Delta \varepsilon_{v d}
$$

where $\Delta u$ is pore pressure increment, $C_{b}$ is bulk compressibility, and $\Delta \varepsilon_{v d}$ is the plastic volumetric strain increment. The referred model can adequately reflect the response of pore pressure until liquefaction triggering point [17] and thus is an effective tool for assessment of soil liquefaction risk.

The plastic volumetric strain increment could be obtained by various constitutive theories. In this paper, the expression presented by Byrne [18] was adopted. The plastic volumetric strain increment was expressed as follows:

$$
\frac{\Delta \varepsilon_{v d}}{\gamma}=C_{1} \exp \left(-C_{2} \frac{\varepsilon_{v d}}{\gamma}\right),
$$

where $\gamma$ is the shear strain in the current cycle, $\varepsilon_{v d}$ is the accumulated volumetric strain from prior cycles, and $C_{1}$ and $C_{2}$ are constants that depend on the relative density $D_{r}$ :

$$
\begin{aligned}
& C_{1}=7600\left(D_{r}\right)^{-2.5}, \\
& C_{2}=\frac{0.4}{C_{1}} .
\end{aligned}
$$

In this paper, the model was incorporated into the finite difference computer program Flac $^{3 \mathrm{D}}$ to perform a nonlinear fully coupled dynamic analysis. Flac ${ }^{3 \mathrm{D}}$ is based on a continuum finite difference discretization using the Lagrangian approach [19]. The equations of motion are utilized to obtain the velocities and displacements when dynamic load is excreted. The equation of motion can be expressed as

$$
\rho \frac{\partial v_{i}}{\partial t}=\frac{\partial \sigma_{i j}}{\partial x_{i}}+\rho b_{i},
$$

where $\rho$ is material density, $t$ is time domain, $x_{i}$ is coordinate vector, $\sigma_{i j}$ is stress tensor, and $b_{i}$ is body force.

For a fully nonlinear method, any given function can be used in dynamic analysis of Flac ${ }^{3 \mathrm{D}}$. The general constitutive equation is expressed as

$$
\dot{\sigma_{i j}}=M\left(\sigma_{i j}, \dot{\varepsilon_{i j}}, \kappa\right)
$$

where $\dot{\sigma}_{i j}$ is stress rate tensor, $\dot{\varepsilon}_{i j}$ is strain rate tensor, $\kappa$ is the parameter taking the loading history into account, and $M$ is the given functional expression.
The Mohr-Coulomb elastic-perfectly plastic constitutive relation is the commonly used constitutive models for soil. In order to adapt the model for dynamic analysis, several modifications have been achieved. In this paper, the modification defined by Puebla et al. [20] was used. The secant shear modulus $G$ and bulk modulus $B$ were considered to be stressdependent and given as follows:

$$
\begin{aligned}
& G=\mathrm{kg} \cdot \mathrm{Pa} \cdot\left(\sigma_{m}^{\prime} / \mathrm{Pa}\right)^{n}, \\
& B=\mathrm{kb} \cdot \mathrm{Pa} \cdot\left(\sigma_{m}^{\prime} / \mathrm{Pa}\right)^{m},
\end{aligned}
$$

where $\mathrm{kg}$ and $\mathrm{kb}$ are shear and bulk modulus numbers, $n$ and $m$ are modulus exponents, $\sigma_{m}^{\prime}$ is the mean effective stress, and $\mathrm{Pa}$ is atmospheric pressure.

\section{Statement of Dam Conditions}

Dongzhen reservoir, located about $6.0 \mathrm{~km}$ upstream Putian City in Fujian Province, Southeastern China, has a normal storage capacity of 435 million $\mathrm{m}^{3}$. The reservoir has a comprehensive function of flood control, irrigation, and power generation. The water retaining dam has an irregular geometry (Figure 1). The longitudinal profile of the dam has an asymmetric $\mathrm{U}$-shape which is steep on the right flank and gentle on the left (Figure 2(a)). The dam is a core-wall earth dam with a maximum height of $58.6 \mathrm{~m}$. The normal dammed water level is about $8.1 \mathrm{~m}$ to the dam crest (Figure 2(b)). The core wall made of lean clay and the filling is gravelly soil. A layer of rock blocks revetment was placed on the surface to protect the slope. The thickness of the blocks revetment on the upstream surface is about $2.0 \mathrm{~m}$.

The dam was built in the 1950s, when there was no seismic design standard in China. The study area is located in the coast of Taiwan Channel. Caused by the movement of the Pacific Plate, a series of NNE and NW fault zones can be found in this area (Figure 3). The area is currently within the region with seismic intensity of 7 based on Chinese Standard [21]. According to the seismic safety analysis completed by Fujian Provincial Institute of Geological Engineering Investigation, the equivalent earthquake magnitude which affects the dam area is Ms 6.5 and the epicenter distance is about $50 \mathrm{~km}$. The peak bedrock acceleration of the maximum credible earthquake is about $158 \mathrm{gal}$. Owing to the high public interest and the large amount of potentially affected persons, questions about the seismic stability of the dam are important to study in detail.

\section{Shear Wave Velocity Test}

In order to study the seismic stability of the dam, the first step is to evaluate the liquefaction potential of gravelly soils [11]. The usually available field test methods are the standard penetration test (SPT), the cone penetration test (CPT), in situ shear wave velocity measurement $\left(V_{s}\right)$, and the Becker penetration test (BPT) [22]. Among these approaches, the shear wave velocity measurement is more feasible in gravelly soil field because this type of soil is difficult to penetrate $[10,22,23]$. A three-component geophone setup was placed in a $30 \mathrm{~m}$ deep borehole to obtain the shear wave velocity 


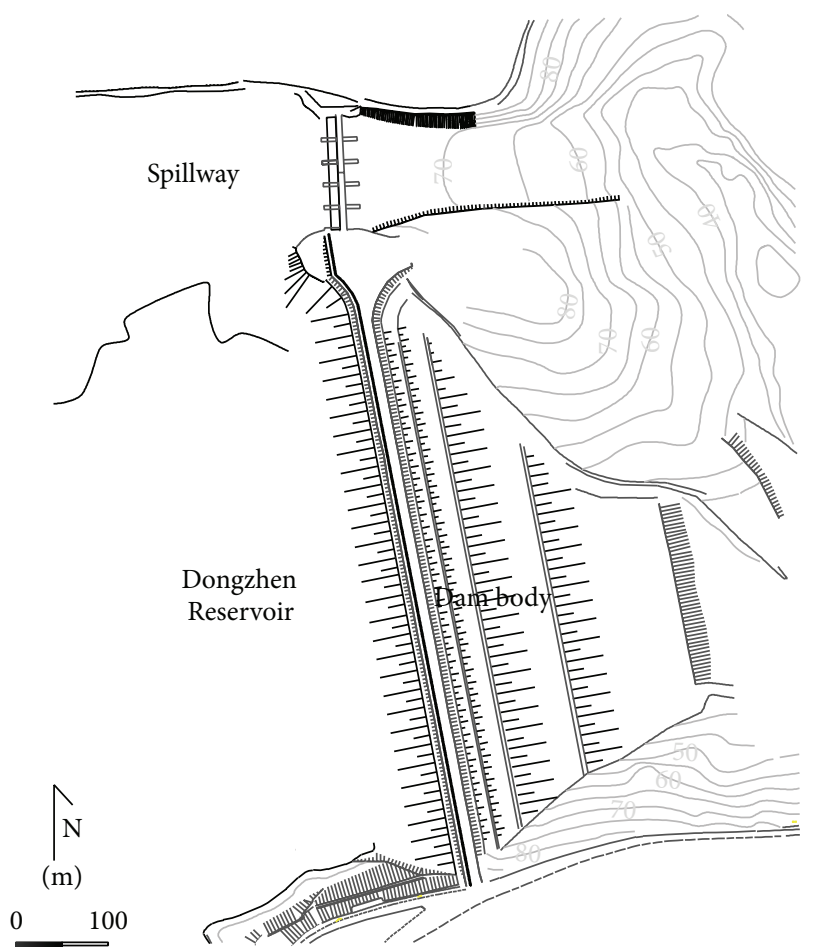

FIgURE 1: Plane view of Dongzhen Reservoir dam.

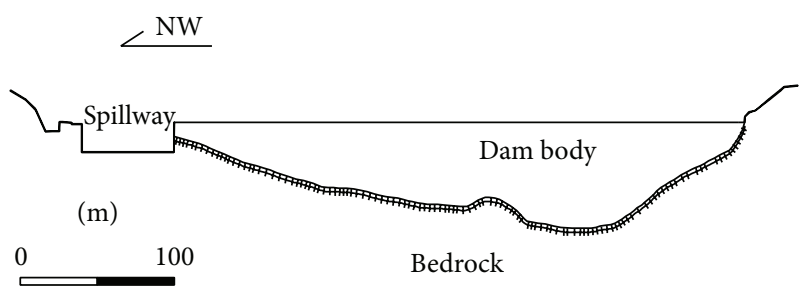

(a)

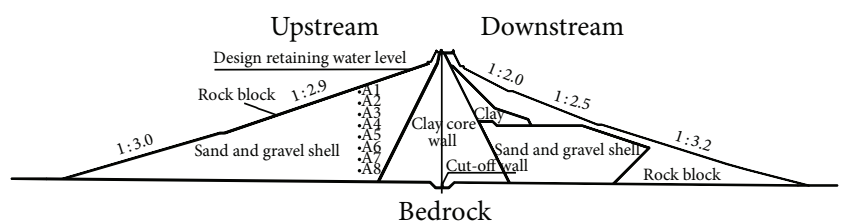

(m)

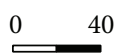

(b)

Figure 2: Longitudinal (a) and cross (b) section of Dongzhen Reservoir dam. Al-A8 denote the location for excess pore pressure ratio analysis.

at different depths. According to Chinese Standard [24], the soils can be determined as nonliquefiable when the measured shear wave velocity is greater than calculated limit shear wave velocity. The limit shear wave velocity can be calculated from the following empirical equation:

$$
V_{s t}=291 \cdot \sqrt{K_{h} \cdot Z \cdot r_{d}}
$$

where $V_{s t}$ is the limit shear wave velocity, $K_{h}$ is the peak acceleration coefficient, the value is 0.1 for the field with

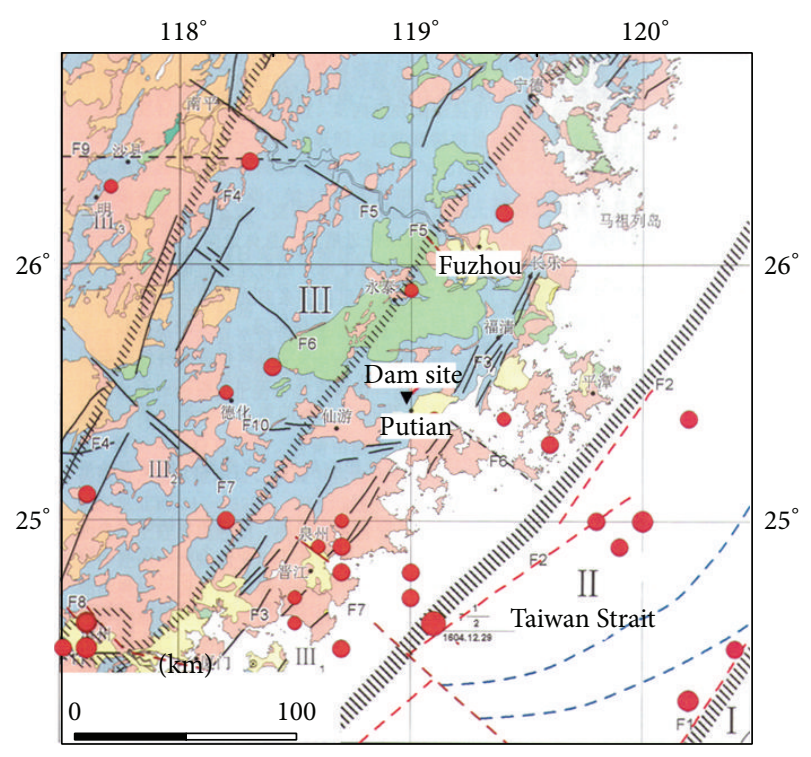

F1: Eastern Taiwan Strait fault zone

F2: Seashore fault zone

F3: Changle-Shaoan fault zone

F4: Zhenghe-Haifeng fault zone

F5: Minjiang river fault zone

F6: Shaxian-Nanri island fault zone

F7: Yongan-Jinjiang river fault zone

F8: Jiulong river fault zone

F9: Shaxian-Lianjiang river fault zone

F10: Zhangping-Putian fault zone

F11: Nanjing-Xiamen fault zone

I: Taiwan upwelling zone

II: Taiwan Strait subsiding zone

III: Wuyi-Daiyun upwelling zone

$\mathrm{III}_{1}$ : Eastern Fujian upwelling zone

$\mathrm{III}_{2}$ : Central Fujian upwelling zone

$\mathrm{III}_{3}$ : Western Fujian upwelling zone

- Earthquake epicenter

$\square$ Quaternary formation

$\square$ Cretaceous formation

$\square$ Jurassic formation

$\square$ Triassic formation

$\square$ Granite

FIGURE 3: Geological map of the study area.

seismic intensity of $7, Z$ refers to the depth, and $r_{d}$ can be calculated as follows:

$$
\begin{array}{ll}
r_{d}=1.0-0.01 Z & \text { when } Z=0 \sim 10 \mathrm{~m}, \\
r_{d}=1.1-0.02 Z & \text { when } Z=10 \sim 20 \mathrm{~m}, \\
r_{d}=0.9-0.01 Z & \text { when } Z=20 \sim 30 \mathrm{~m} .
\end{array}
$$

The measured and calculated results are listed in Table 1. It can be concluded that the upstream gravelly filling has the possibility of liquefaction below the depth of $12.0 \mathrm{~m}$.

\section{Liquefaction Assessment and Deformation Analysis}

5.1. Numerical Modeling and Parameters. The detailed seismic response of Dongzhen Reservoir dam was simulated 
TABLE 1: Liquefaction judgment using shear wave velocity test.

\begin{tabular}{lcccc}
\hline Number & Depth $(\mathrm{m})$ & $\begin{array}{c}\text { Measured shear wave } \\
\text { velocity }(\mathrm{m} / \mathrm{s})\end{array}$ & $\begin{array}{c}\text { Limit shear wave } \\
\text { velocity }(\mathrm{m} / \mathrm{s})\end{array}$ & $\begin{array}{c}\text { Primary liquefaction } \\
\text { estimation }\end{array}$ \\
\hline 1 & $2-4$ & 315 & 157 & Nonliquefiable \\
2 & $4-6$ & 292 & 201 & Nonliquefiable \\
3 & $6-8$ & 305 & 235 & Nonliquefiable \\
4 & $8-10$ & 315 & 263 & Nonliquefiable \\
5 & $10-12$ & 296 & 286 & Nonliquefiable \\
6 & $12-14$ & 300 & 304 & Liquefiable \\
7 & $14-16$ & 285 & 319 & Liquefiable \\
8 & $16-18$ & 314 & 331 & Liquefiable \\
9 & $18-20$ & 287 & 340 & Liquefiable \\
10 & $20-22$ & 302 & 350 & Liquefiable \\
11 & $22-24$ & 303 & 361 & Liquefiable \\
12 & $24-26$ & 304 & 371 & Liquefiable \\
13 & $26-28$ & 304 & 380 & Liquefiable \\
14 & $28-30$ & 288 & 387 & Liquefiable \\
\hline
\end{tabular}

using software $\mathrm{Flac}^{3 \mathrm{D}}$. A three-dimensional modeling of the dam was established (Figure 4). $x$-axis of the model was set along the river, $y$-axis was set perpendicular to the river center line, and the positive $z$-axis was set upward. A field seismic wave provided by Fujian Provincial Institute of Geological Engineering Investigation was used in this paper for dam seismic response analysis. The seismic wave was selected from historical seismic wave database considering similar field condition and potential influence of the epicenter. The seismic acceleration was recorded from the Ms 6.6 Imperial Valley Earthquake in 1979 at an epicenter distance of $57.6 \mathrm{~km}$. The peak seismic acceleration is $189 \mathrm{gal}$. The horizontal acceleration time history was shown in Figure 5. The viscous absorb boundary, developed by Lysmer and Kuhlemeyer [25], was used to absorb the unbalanced energy at the boundary. In view of the large permeability difference between the clay and gravelly soil, the clay core wall was considered as impermeable layer. The phreatic water level was used and normal retaining water level of the reservoir was $8.1 \mathrm{~m}$ below the dam crest. The hydrostatic pressure caused by the retaining water was applied to the upper stream surface of the dam.

The analysis was conducted in two steps. First, the static analysis was carried out. The Mohr-Coulomb model with stress-dependent materials properties was used for all the parts of the dam. The materials properties of the dam are given in Table 2. In the second step, the effective stress model was applied to the upstream gravelly soil, and the MohrCoulomb model was still used for the rest parts. The relative density $\left(D_{r}\right)$ of the upstream gravelly soil used in the Byrne model was obtained by field test and the mean value is $67.5 \%$.

In order to illustrate the liquefaction degree of the gravelly soil, the excess pore pressure ratio $R_{u}$ was defined and denoted as

$$
R_{u}=\frac{U_{e}}{\sigma_{m 0}^{\prime}},
$$

where $U_{e}$ is the excess pore pressure during the earthquake and $\sigma_{m 0}^{\prime}$ is the mean effective stress in the static condition.

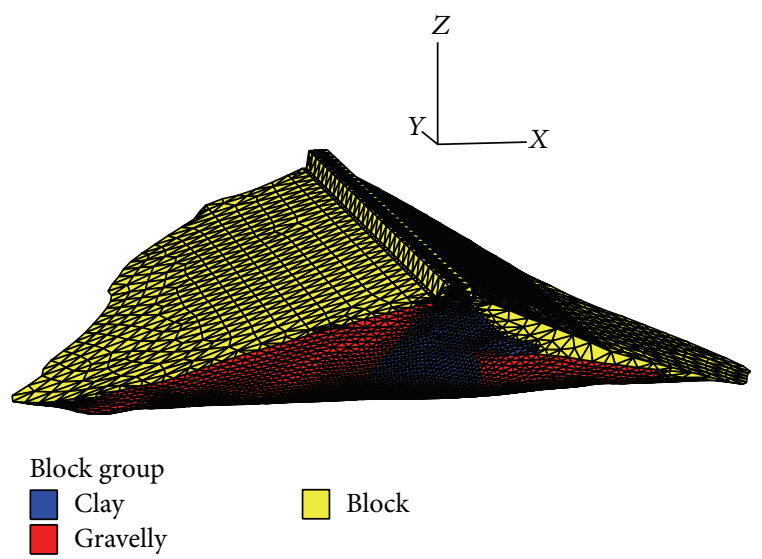

Figure 4: Three-dimensional finite difference mesh of Dongzhen Reservoir dam.

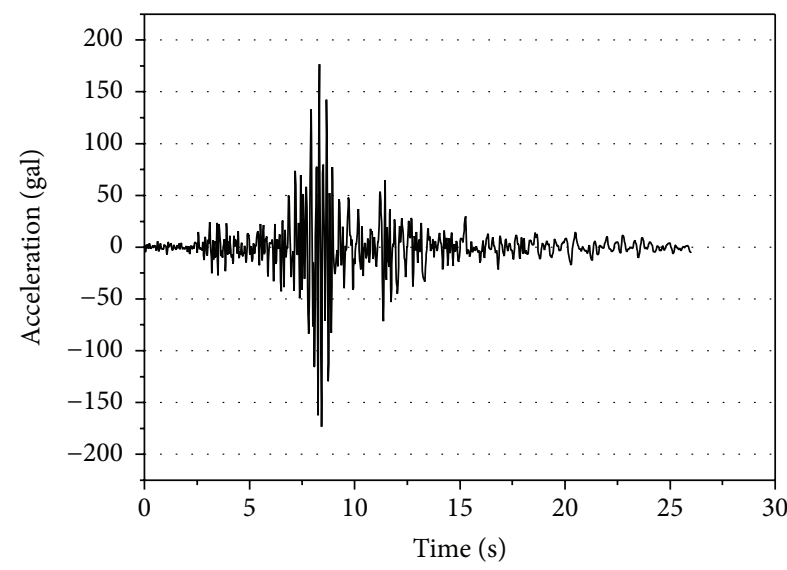

FIGURE 5: Input earthquake acceleration record.

$R_{u}=1.0$ represents a fully liquefied state and $R_{u}=0.0$ represents a static condition. 


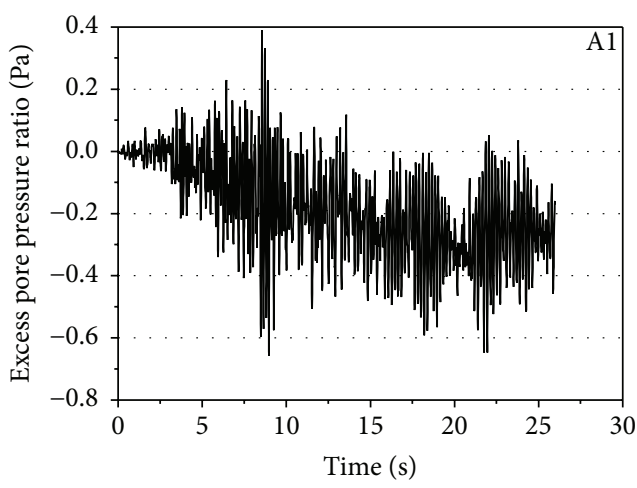

(a)

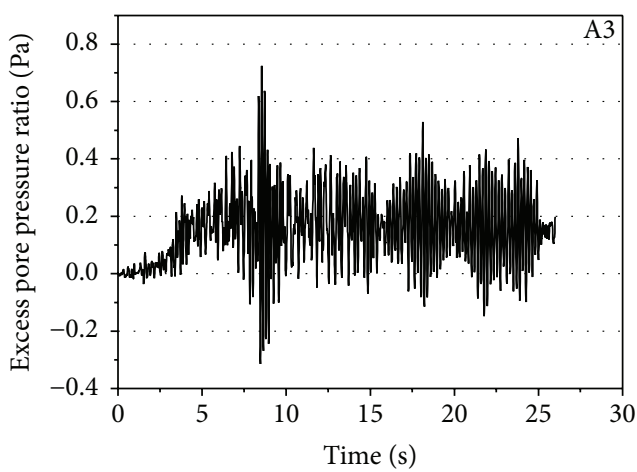

(c)

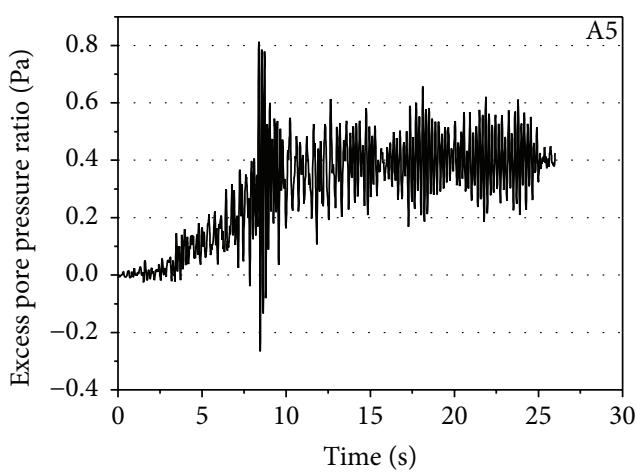

(e)

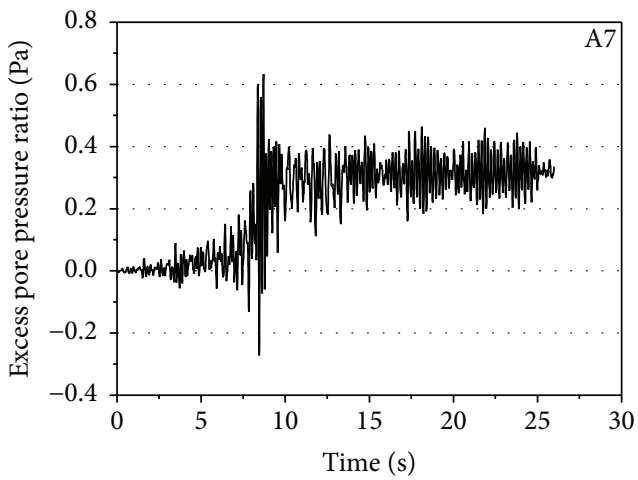

(g)

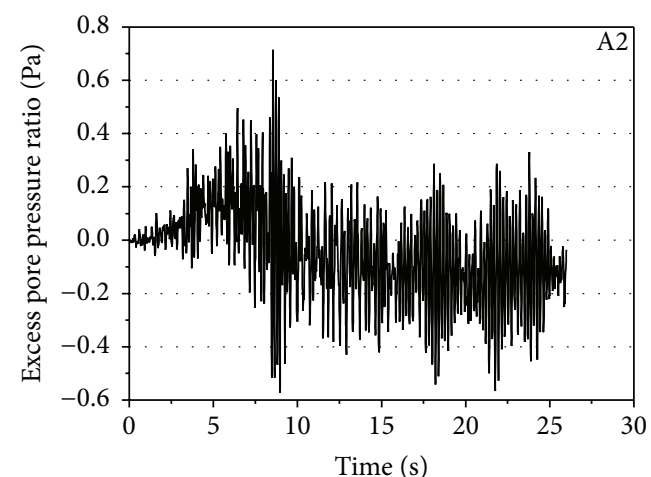

(b)

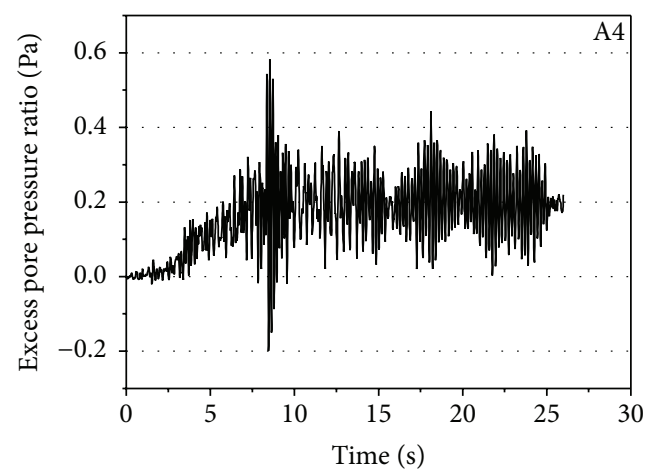

(d)

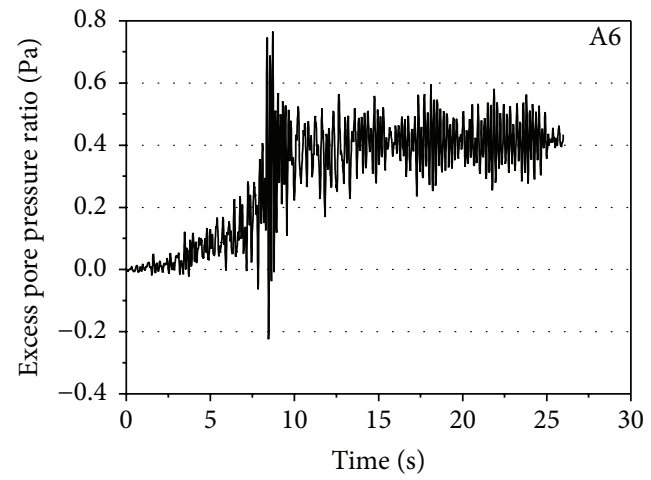

(f)

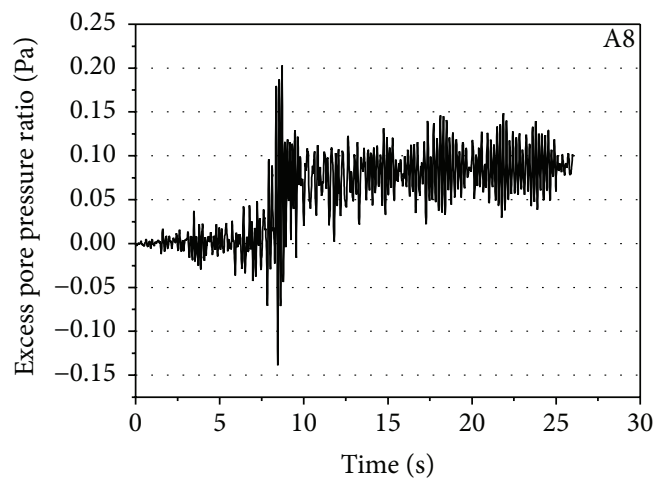

(h)

FIGURE 6: Excess pore pressure ratio of upstream gravelly soil at points A1 to A8. The location of points A1 to A8 is shown in Figure 2(b). 
TABLE 2: Properties of the soils used in the numerical modeling.

\begin{tabular}{|c|c|c|c|c|c|c|c|c|}
\hline Material & $\begin{array}{c}\text { Unit } \\
\text { weight } / \mathrm{kN} / \mathrm{m}^{3}\end{array}$ & $\begin{array}{c}\text { Shear modulus } \\
\text { numbers }\end{array}$ & $\begin{array}{c}\text { Shear modulus } \\
\text { exponent }\end{array}$ & $\begin{array}{l}\text { Bulk modulus } \\
\text { numbers }\end{array}$ & $\begin{array}{l}\text { Bulk modulus } \\
\text { exponents }\end{array}$ & Cohesion $/ \mathrm{kPa}$ & $\begin{array}{c}\text { Friction } \\
\text { angle } /^{\circ}\end{array}$ & $\begin{array}{l}\text { Permeability } \\
\text { coefficient } \mathrm{cm} / \mathrm{s}\end{array}$ \\
\hline Clay & 19.5 & 490 & 0.50 & 1470 & 0.50 & 48.0 & 24.0 & $7.50 \times 10^{-6}$ \\
\hline Gravel & 20.0 & 1200 & 0.63 & 3600 & 0.63 & 0.0 & 37.0 & $5.22 \times 10^{-2}$ \\
\hline Block & 22.0 & 1050 & 0.69 & 3150 & 0.69 & 0.0 & 45.0 & 0.55 \\
\hline
\end{tabular}

5.2. Result of the Analyses. The responses of the saturated gravelly soil in terms of excess pore pressure ratio $\left(R_{u}\right)$ at different depths are presented in Figure 6. The relative positions selected for illustration are shown in Figure 2. The distance of the positions is about $5.0 \mathrm{~m}$ and the depth of point $\mathrm{A} 1$ is about $2.0 \mathrm{~m}$ which is just below the rock block revetment layer. Figure 6 indicates that negative excess pore pressure ratio developed in the upper part of the saturated gravelly filling, which means a decrease of pore pressure and increase of effective stress. This phenomenon coincides with the dynamic behavior research of moderate dense granular material with low confining stress [26]. The increase of effective stress prevents the occurrence of potential liquefaction in this range. This conclusion also coincides with the result of in situ shear wave test. Below the depth of $12.0 \mathrm{~m}$, only positive excess pore pressures were built up during the earthquake. The excess pore pressures ratios increase sharply in the time 7.5 to $10 \mathrm{~s}$, corresponding to the period of strong shaking, and then level off. The permanent mean excess pore pressure ratio increases with depth and then decreases. The maximum permanent mean excess pore pressure ratio is less than 0.45 , which means that upstream saturated gravelly filling cannot reach a fully liquefied state.

Figure 7 illustrates the time history of the maximum horizontal displacement in the upstream gravelly soil of the dam. We can observe that the permanent displacement is relatively small. The maximum horizontal displacement of the upstream filling occurs at middle slope with a value about $7.3 \mathrm{~cm}$. The deformations are tolerable and do not have significant influence on the service function of the whole dam according to Hynes-Griffin and Franklin [27].

\section{Conclusion and Discussion}

Soil liquefaction resulting from earthquake shaking is a major cause of damage in earth dam engineering. The field of soil liquefaction research is now only semimatured. The generally used liquefaction assessment methods include laboratory test, empirical relationships base on in situ test indexes, and numerical modeling analyses. Laboratory tests sometimes are too complicated and expensive to be used in engineering. Also, undisturbed test samples are difficult to collect and store. These two aspects restrict the wide use of laboratory tests. The empirical judgments only need several in situ test indexes. Empirical relationships were established based on numerous field cases and accordingly can give a reasonable result in liquefaction estimation. Thus, the empirical judgment is the dominated method at present. But the empirical methods can only provide overall seismic response estimation. The history of soil strength and deformation during

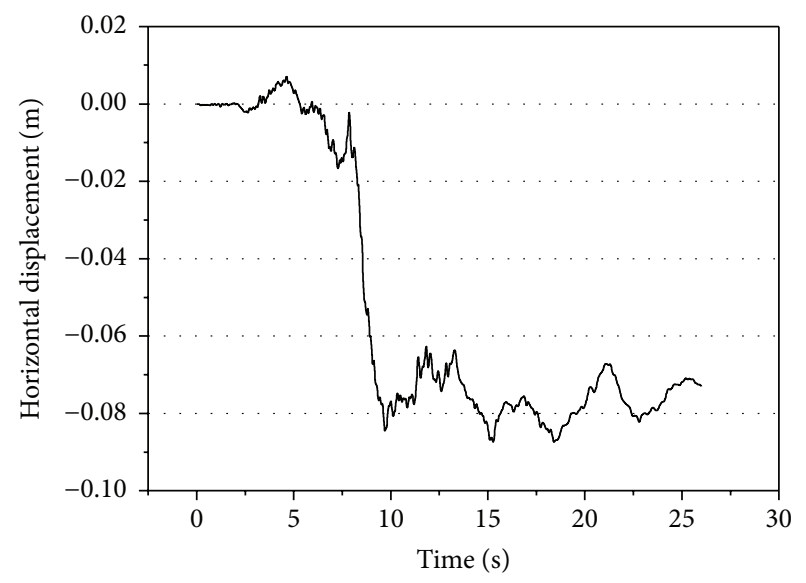

Figure 7: Time history of maximum horizontal displacement in upstream gravelly soil.

earthquake cannot be reflected in empirical relationships. Oppositely, numerical modeling can adopt more complex geometrical, stress history and constitutive models and can easily give the results of effective stress, shear strain, and deformation at any time. So it is more feasible for detailed seismic performance analysis.

Dongzhen Reservoir water retaining dam is only $6.0 \mathrm{~km}$ upstream the Putian City. The stability of the dam has drawn great concerns. The result of in situ shear wave velocity test demonstrates that the gravelly filling has liquefaction potential under an earthquake of intensity 7. In order to thoroughly investigate the seismic response of the dam, threedimensional finite difference technique was adopted in this paper. The results suggest that negative excess pore pressure developed in the upper part of the saturated gravelly filling, which means that the gravelly soil is not likely to liquefy above the depth of $12.0 \mathrm{~m}$. Below this depth, positive excess pore pressure developed and the maximum excess pore pressure ratio appears at the depth of about $22.0 \mathrm{~m}$. The maximum excess pore pressure ratio rises to about 0.45 . This means that the gravelly soil cannot reach a fully liquefied state. The displacement in upstream saturated gravelly filling is relatively small and tolerable. The deformation would not have significant impact on the overall stability of the dam. The gravelly filling still can maintain its seismic resistance.

\section{Conflict of Interests}

The authors declare that there is no conflict of interests regarding the publication of this paper. 


\section{Acknowledgments}

The authors would like to gratefully acknowledge the financial support provided by National Natural Science Foundation of China (no. 41272328). The authors also wish to thank the reviewers for their instructive comments.

\section{References}

[1] J. G. Gao, "Earthquake-caused-damages of reservoirs in China and countermeasures against them," Journal of Disaster Prevention and Mitigation Engineering, vol. 23, pp. 81-91, 2003 (Chinese).

[2] H. B. Seed, P. A. De Alba, and F. I. Makdisi, "Performance of earth dams during earthquakes," Journal of the Geotechnical Engineering Division, vol. 104, pp. 967-994, 1978.

[3] H. B. Seed, K. L. Lee, I. M. Idriss, and F. I. Makdisi, “The slides in the San Fernando dams during the earthquake of February 9, 1971," Journal of the Geotechnical Engineering Division, vol. 101, no. 7, pp. 651-688, 1975.

[4] X. Z. Ling, L. X. Wang, and H. Zhou, "Ascertainment of sand liquefaction arising from earthquake by the method of comprehensive stress: taking seismic damage to Baihe principal dam of Miyun reservoir in Beijing, China, as an example," Earthquake Engineering and Engineering Vibration, vol. 21, pp. 99-104, 2001 (Chinese).

[5] R. Dobry and L. Alavarez, "Seismic failures of Chilean tailings dams," Journal of the Soil Mechanics and Foundations Division, vol. 93, pp. 237-260, 1967.

[6] S. Okusa and S. Anma, "Slope failures and tailings dam damage in the 1978 Izu-Ohshima-Kinkai earthquake," Engineering Geology, vol. 16, no. 3-4, pp. 195-224, 1980.

[7] E. L. Krinitzsky and M. E. Hynes, “The Bhuj, India, earthquake: lessons learned for earthquake safety of dams on alluvium," Engineering Geology, vol. 66, no. 3-4, pp. 163-196, 2002.

[8] H. A. Taiebat and J. P. Carter, "A semi-empirical method for the liquefaction analysis of offshore foundations," International Journal for Numerical and Analytical Methods in Geomechanics, vol. 24, no. 13, pp. 991-1011, 2000.

[9] R. D. Andrus, P. Piratheepan, B. S. Ellis, J. Zhang, and C. H. Juang, "Comparing liquefaction evaluation methods using penetration-VS relationships," Soil Dynamics and Earthquake Engineering, vol. 24, no. 9-10, pp. 713-721, 2004.

[10] I. M. Idriss and R. W. Boulanger, "Semi-empirical procedures for evaluating liquefaction potential during earthquakes," Soil Dynamics and Earthquake Engineering, vol. 26, no. 2-4, pp. 115130, 2006.

[11] H. B. Seed, K. O. Cetin, R. E. S. Moss et al., "Recent advances in soil liquefaction engineering: a unified and consistent framework," in Proceedings of the 26th Annual ASCE Los Angeles Geotechnical Spring Seminar, Keynote Presentation, Long Beach, Calif, USA, 2003.

[12] Z.-L. Wang, F. I. Makdisi, and J. Egan, "Practical applications of a nonlinear approach to analysis of earthquake-induced liquefaction and deformation of earth structures," Soil Dynamics and Earthquake Engineering, vol. 26, no. 2-4, pp. 231-252, 2006.

[13] J.-M. Zhang and G. Wang, "Large post-liquefaction deformation of sand, part I: physical mechanism, constitutive description and numerical algorithm," Acta Geotechnica, vol. 7, no. 2, pp. 69-113, 2012.
[14] W. F. Marcuson, "Definition of terms related to liquefaction," Journal of the Geotechnical Engineering Division, vol. 104, pp. 1197-1200, 1978.

[15] D. S. Liyanapathirana and H. G. Poulos, "A numerical model for dynamic soil liquefaction analysis," Soil Dynamics and Earthquake Engineering, vol. 22, no. 9-12, pp. 1007-1015, 2002.

[16] G. R. Martin, W. D. L. Finn, and H. B. Seed, "Fundamentals of liquefaction under cyclic loading," ASCE Journal of the Geotechnical Engineering Division, vol. 101, no. 5, pp. 423-438, 1975.

[17] P. M. Byrne, E. Naesgaard, and M. Seid-Karbasi, "Hardy lecture-analysis and design of earth structures to resist seismic soil liquefaction," in Proceedeings of the 59th Canadian Geotechnical Conference, pp. 1-24, Vancouver, Canada, 2006.

[18] P. Byrne, "A cyclic shear-volume coupling and pore-pressure model for sand," in Proceedings of the 2nd International Conference on Recent Advances in Geotechnical Earthquake Engineering and Soil Dynamics, pp. 47-55, Geotechnical Special Rublication, St. Louis, Mo, USA, 1991.

[19] Itasca Consulting Group, FLAC ${ }^{3 D}$-Fast Lagrangian Analysis of Continua in Three Dimensions-User's Guide, Itasca Consulting Group, 2005.

[20] H. Puebla, P. M. Byrne, and R. Phillips, "Analysis of CANLEX liquefaction embankments: prototype and centrifuge models," Canadian Geotechnical Journal, vol. 34, no. 5, pp. 641-657, 1997.

[21] GB/T 18306, Seismic Ground Motion Parameter Map of China, 2001, (Chinese).

[22] T. L. Youd and S. K. Noble, "Liquefaction criteria based on statistical and probabilistic analyses," in Proceedings of the NCEER Workshop on Evaluation of Liquefaction Resistance of Soils, pp. 201-205, 1997.

[23] R. D. Andrus and K. H. Stokoe, "Liquefaction resistance of soils from shear-wave velocity," Journal of Geotechnical and Geoenvironmental Engineering, vol. 126, no. 11, pp. 1015-1025, 2000.

[24] GB 50487, Code for Engineering Geological Investigation of Water Resources and Hydropower, China Plan Publishing Company, Beijing, China, 2008, (Chinese).

[25] J. Lysmer and R. L. Kuhlemeyer, "Finite dynamic model for infinite media," Journal of the Engineering Mechanics Division, vol. 95, no. 4, pp. 859-878, 1969.

[26] M. R. Madhav and A. M. Krishna, "Liquefaction mitigation of sand deposits by granular piles-an overview," in Geotechnical Engineering for Disaster Mitigation and Rehabilitation: Proceedings of the 2nd International Conference GEDMAR08, Nanjing, China 30 May-2 June, 2008, pp. 66-79, Springer, Berlin, Germany, 2008.

[27] M. E. Hynes-Griffin and A. G. Franklin, "Rationalizing the seismic coefficient method," Miscellaneous Paper GL-84-13, U.S. Army Corps of Engineers Waterways Experiment Station, Vicksburg, Miss, USA, 1984. 


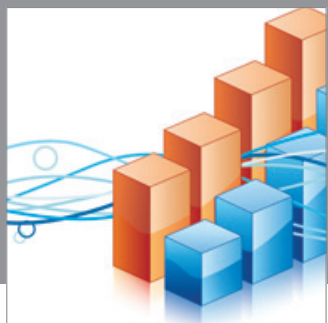

Advances in

Operations Research

mansans

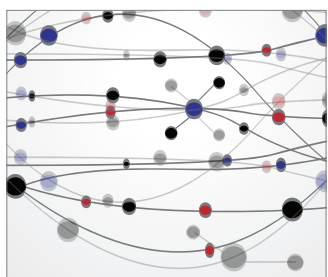

The Scientific World Journal
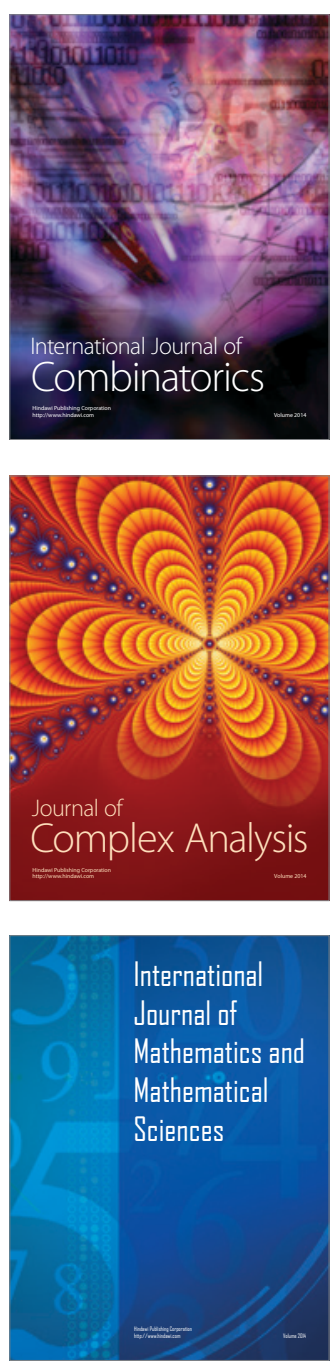
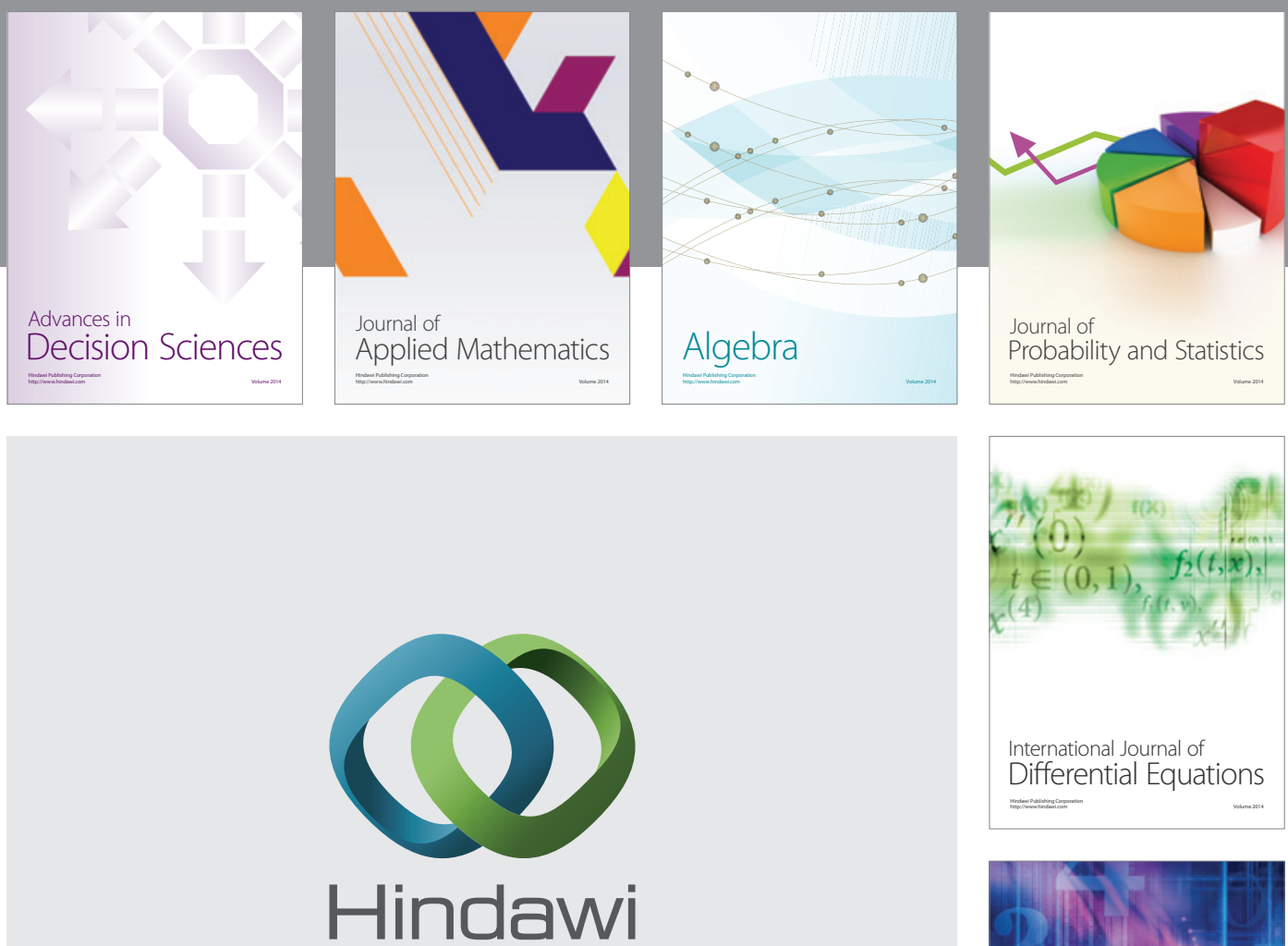

Submit your manuscripts at http://www.hindawi.com
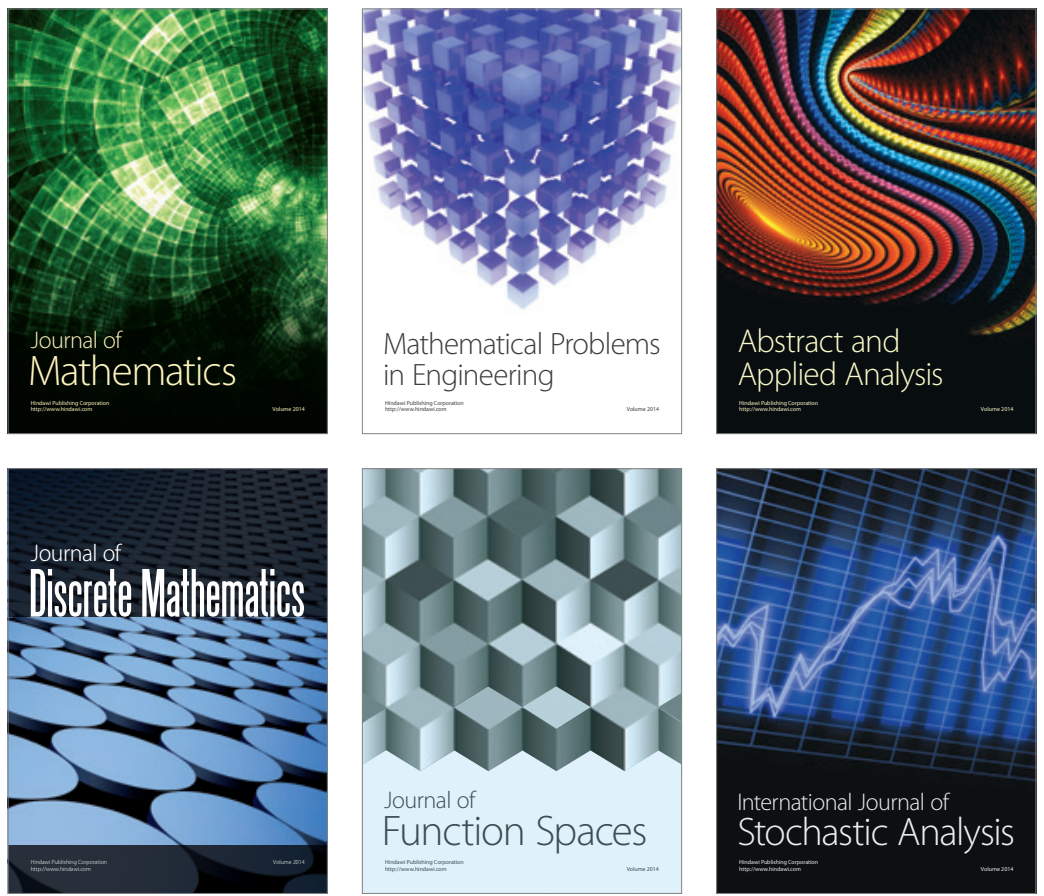

Journal of

Function Spaces

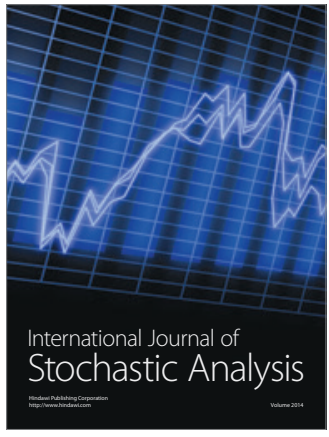

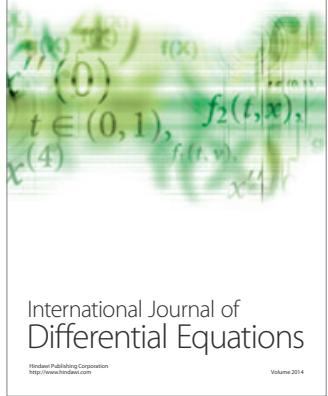
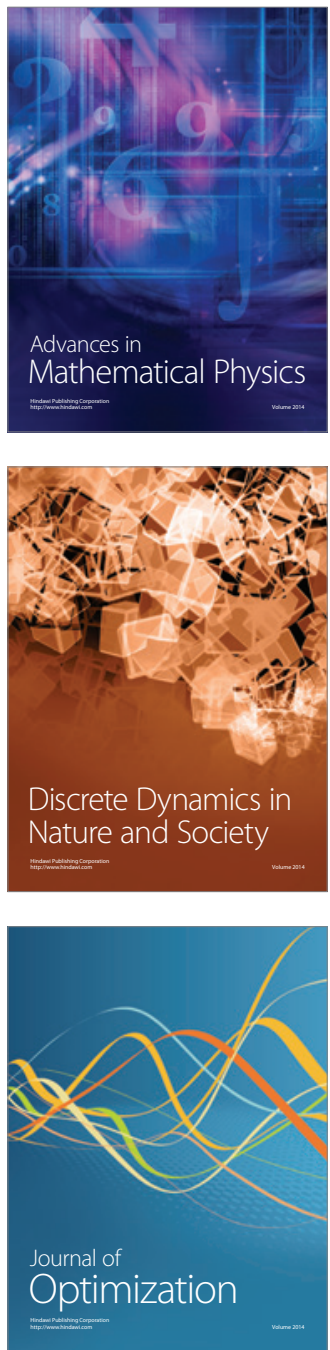